\section{La misteriosa enfermedad de Charles Darwin}

\section{The misterious disease that affected to Charles Darwin}
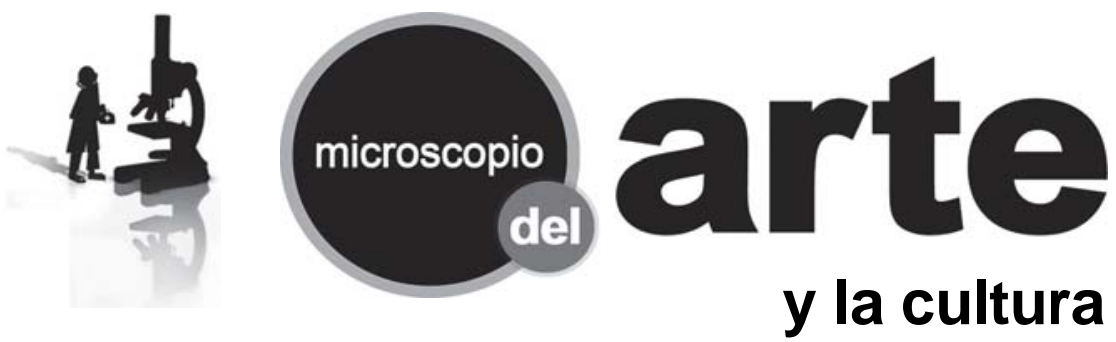
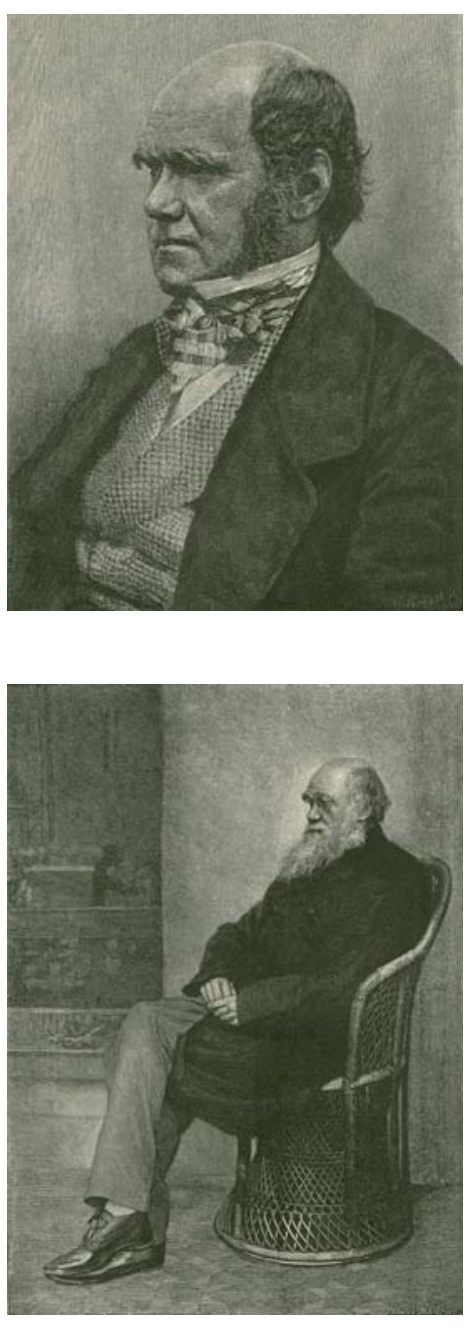

En su viaje alrededor del mundo, travesía que duró largos cinco años (diciembre 1831 a octubre 1836) a bordo del bergantín Beagle del gobierno inglés, designado en su condición de naturalista, Charles Robert Darwin arribó a las costas chilenas en julio de 1834 y permaneció en el país por un año, hasta julio de 1835. Durante ese tiempo recorrió gran parte de la zona central, además de Chiloé, las islas Guaitecas y el archipiélago de Los Chonos. Antes de recorrer el Norte Chico, realizó un breve viaje a Mendoza.

En su libro "Viaje de un naturalista alrededor del mundo", en el capítulo "Nubes de langostas. La Benchuca, enorme chinche negra de las Pampas", notas del día 25 de marzo 1835, fecha en la cual se encontraba en Chile describe lo siguiente: "Durante la noche hube de sostener una lucha, y no es una exageración, contra una benchuca (sic) especie de Reduvius, la gran chinche negra de las pampas. ¿Qué asco no experimentará uno cuando siente que le recorre el cuerpo un insecto blando, que tiene por lo menos una pulgada de largo?... Su picadura no produce ningún dolor, y es curioso ver como se va hinchando su cuerpo; de plano que es, en menos de diez minutos se convierte en una bola."

A su regreso a Inglaterra, Darwin se mantuvo asintomático hasta 1841 cuando comienza a manifestar síntomas cardíacos y gastrointestinales, los que empeoran hasta afectarlo gravemente, de modo que se mantuvo por largos períodos prácticamente recluido en su casa, afectado por episodios de taquicardia, fatigabilidad, vómitos, disfagia y dolor abdominal. Fallece de un ataque cardíaco el 19 de abril de 1882.

Con el paso de los años se ha asociado lo descrito en el capítulo "Nubes de langostas........." con la condición de salud que se fue manifestando en Darwin, esta hipótesis fue propuesta en primer lugar por el parasitólogo Saúl Adler en 1959, y luego por Ralph Bernstein en 1984, planteando la hipótesis de que los males de Darwin se originaron en el Mal de Chagas, afección contraída en sus viajes por Chile y Argentina, zona endémica de la enfermedad.

No fue hasta 1909 cuando el brillante médico brasileño Carlos Chagas describió en forma completa esta enfermedad, desconocida para los grandes médicos ingleses que en vano intentaron curar a Charles Darwin.

¿Sería entonces correcto afirmar que Darwin estaba afectado en forma crónica de la enfermedad de Chagas, patología que finalmente lo llevaría a la muerte?

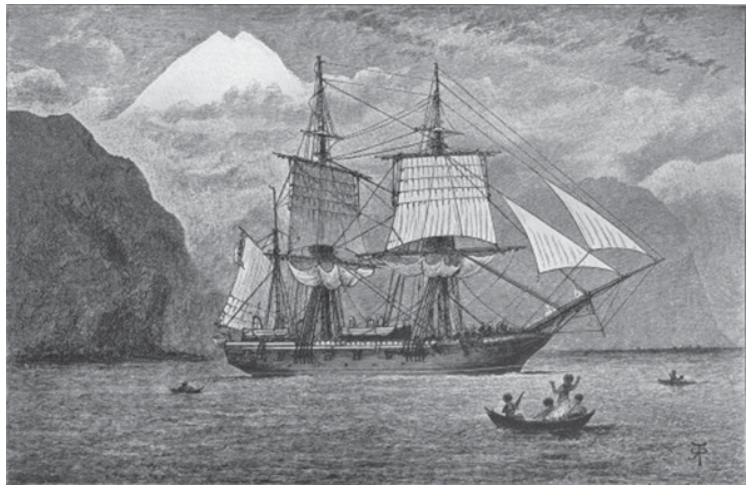

Contribución de: Ernesto Payá G y Dalma Domic T.

\section{Referencias}

1.- Darwin C. Viaje de un naturalista alrededor del mundo; Editorial El Ateneo, Buenos Aires, 1945.

2.- Bernstein RE, Darwin's illness: Chagas' disease resurgens. J Royal Soc Med 1984; 77 (July): 608-9.

Fotografías: Reproducidas con permiso de John van Wyhe ed., The Complete Work of Charles Darwin Online (http://darwin-online.org.uk/) 